\title{
INTEGRATING GENDER IN RESEARCH PLANNING
}

\section{WHY IS THIS IMPORTANT?}

Did you know that research can open doors for more gender equitable futures? This is only possible if you integrate a clear and strong gender analysis when planning your research. Gender analysis is built on an understanding of the differences and inequalities in the interrelated lives of women, men, and members of other gender diverse groups, often shaped by unequal power relations and norms that dictate what roles, attitudes and behaviours are considered normal or appropriate.

Gender blind research is just bad research. Not only does it risk undermining the reliability and validity of the findings and their representation of social realities, but it can also cause the programmes, policies and campaigns on which the research is based to reinforce rather than challenge patriarchal structures and gender inequalities.

If you want your research to contribute to a gendered understanding, then the first step is a strong research plan. This will define the entire research process: background, rationale, scope, methodology and use. But we know that it can be difficult integrating gender throughout the research cycle. This guideline has been developed to support researchers to assess and further strengthen the gender perspective in their research planning. It can also be a useful tool for the reviewers involved in the peer review process.

We recommend that you use this guideline in conjunction with Oxfam's guideline on Writing Terms of Reference for Research, along with the Terms of Reference for Research Template, both of which incorporate elements of the rubric presented here. It should also be read in conjunction with our Research for Influencing diagram.

\section{REVIEWING YOUR RESEARCH DESIGN FROM A GENDER PERSPECTIVE}

The table below presents the gender rubric developed by the Gender Working Group of the Oxfam Research Network. This is an adaptation of the Interagency Gender Working Group's Gender Integration Continuum Categories designed specifically for programming. The rubric presents a sliding scale that can be used to help identify how integrated gender is in your research.

The rubric starts from gender-blind, where the research fails to acknowledge any gender issues, and moves towards gender-transformative, where the research findings are meant to catalyse social change. Ideally, research should aim to be at the gender-transformative end of the spectrum. Research that is gender-transformative has the potential to inform long-term practical changes in 
structural power relations and norms, and reduce gender inequality. Most research falls somewhere on a scale that runs from gender-aware to gender-transformative, though we sometimes run the risk of falling into the trap of gender-blind research by failing to acknowledge and question gender issues.

Oxfam's strategic plan highlights gender as one of its top priorities, emphasizing the importance of stand-alone work on gender justice that contributes to putting women's rights at the heart of all we do. Therefore, all research within Oxfam should be at least gender-aware, and this standard is recommended throughout the sector.

Use the scale outlined in the table below to identify where your research can or should be located. Be honest with yourself - where do you want it to be and where is it now? The next section will help you do a refined assessment of your research project.

\begin{tabular}{|l|l|}
\hline Gender Research Rubric \\
\hline Gender-blind & $\begin{array}{l}\text { Gender (the differentiated and intersectional experiences of women, } \\
\text { men, and gender diverse groups) is not considered in the research } \\
\text { project; not even in its conceptualization or its rationale. }\end{array}$ \\
\hline Gender-aware & $\begin{array}{l}\text { Gender is considered in the research project's rationale, but is not an } \\
\text { operative concept in the design and methodology. }\end{array}$ \\
\hline Gender-sensitive & $\begin{array}{l}\text { Gender is considered in the research project's rationale, project } \\
\text { design and methodology. Data is disaggregated by gender, and } \\
\text { gender is also considered in the composition of the research team } \\
\text { and reviewers. Gender-sensitive research does not (yet) extend to } \\
\text { analysis and action to address gender inequalities. }\end{array}$ \\
\hline Gender-responsive & $\begin{array}{l}\text { Gender is considered in the research project's rationale, design, and } \\
\text { methodology and is rigorously analysed with a view to inform } \\
\text { implementation, communication, and influencing strategies. Gender- } \\
\text { responsive research does not (yet) address the underlying structural } \\
\text { factors such as norms and power relations that contribute } \\
\text { to gender inequalities. }\end{array}$ \\
\hline $\begin{array}{l}\text { Gender- } \\
\text { transformative }\end{array}$ & $\begin{array}{l}\text { Examines, analyses, and builds an evidence base to inform long-term } \\
\text { practical changes in structural gender power relations and norms, } \\
\text { roles and inequalities. Gender-transformative research should lead to } \\
\text { sustained change through action (e.g. partnerships, outreach, and } \\
\text { interventions, particularly with women's rights organizations). }\end{array}$ \\
\hline
\end{tabular}

\section{GENDERING YOUR RESEARCH: A CHECKLIST}

The questions below can be used as a checklist to assess where your research falls on the rubric and what more you need to consider to meet the requirements of each level. The criteria have been organized to mirror the different stages of the research cycle. Note that you are building on the criteria as you move from gender-aware to gender-transformative so always start from the beginning (e.g. research that is gender-responsive also needs to meet the criteria for genderaware and gender-sensitive research).

All boxes should be checked for you to advance to the next level of the rubric. 
We have started with gender-aware research rather than gender-blind because awareness of gender dynamics needs to be an integral part of any knowledge initiative. No research should be gender-blind.

\section{Gender-aware research}

\section{General}

- Are you using appropriate terminologies and language, i.e. avoiding terms/classifications that apply exclusively to one sex/reflect gender stereotypes (housewife, fishermen), or using language that assumes only two genders (such as the 'opposite gender/sex', or 'either gender')?

\section{Background and rationale}

- Does this research connect to any of the gender projects/campaigns/programmes in your organization?

- Do you consider the gendered dimensions of your research topic in its conceptualization? For example, in research looking at the impacts of taxation; do you consider how women may be differentially or disproportionately affected, compared with men?

\section{Dissemination, engagement and influencing}

- For internal audiences, will you share your report with gender experts/advisors in your organization?

Explain why your research can't progress to the gender-sensitive category:

\section{Gender-sensitive research}

In addition to all the questions for gender-aware, all the following criteria need to be met:

\section{General}

- Do you consider the gender-specific risks associated with this research and have you designed measures to mitigate against these risks?

- Have you considered the gender balance in the project consortium or team?

- Are you collecting/using gender-disaggregated data whenever possible to fully reflect women, girls, and members of gender-diverse communities' experiences?

\section{Background and rationale}

- Is there a research objective that identifies gendered barriers and seeks solutions? 


\section{Research design}

- Do the research questions explicitly seek to uncover the experiences of women, girls, men, boys, and other gender-diverse communities in relation to each other?

- When thinking of the research or data gaps, do you engage with how gender may play a role in producing such gaps?

\section{Methodology}

- Were women, men, and members of gender-diverse communities considered in the sampling? $\mathrm{Be}$ intersectional: consider also which genders are participating in the research process by, for instance, age, ethnicity, class, income, education level, and make attempts to reach out to a diverse population, especially those from socially excluded groups.

- Does the research use participatory or collaborative approaches or methodologies in the research process (i.e. work with gender-diverse local groups to develop interview questions, facilitate interviews/focus groups, and/or conduct validation workshops)?

- $\quad$ For qualitative methods such as focus groups and interviews, were there gender-specific spaces? Mixed groups can be fine, as long there is an opportunity to have separate spaces for different genders as well. Having these interviews led by facilitators of the corresponding gender is also recommended.

- For quantitative methods, were issues pertinent to women and/or other gender-diverse groups taken into account when developing indicators/categories?

\section{Dissemination and influencing}

- For external audiences, will you reach out to women's organizations, networks, and/or associations? Or sexual diversity and gender-identity organizations, if appropriate?

Explain why your research can't progress to the gender-responsive category:

\section{Gender-responsive research}

In addition to all the questions for gender-aware and gender-sensitive categories, all the following criteria need to be met:

\section{Research design and methodology}

- For quantitative/qualitative methods, are the data collection tools designed to take into account and challenge gender stereotypes and social and cultural factors that may introduce gender bias into the data?

- A few examples include: collection of employment data that excludes informal and unpaid care work, questionnaires that consider head of households to only be men; questions that assume rather than challenge gender stereotypes using terms such as 'housewife' or 'fishermen'; 
questions asked of proxy respondents (usually male heads of household) rather than individuals themselves.

\section{Analysis}

- Does the analysis draw out the critical similarities and differences between men's, women's, and members of gender-diverse communities' experiences of the issue or problem?

- Does the analysis unpack the gender dimensions of social groups; for example, does it unpack 'women' looking at the intersectionalities of income, race, and class?

\section{Dissemination, engagement and influencing}

- Are you presenting the experiences of different genders in a way that captures their diversity? i.e. disaggregating gender differences into smaller categories of race, class, ethnicity, marital status, age, and so on.

Explain why your research can't progress to the gender-transformative category:

\section{Gender-transformative research}

In addition to all the criteria for gender-aware, gender-sensitive and gender-responsive research, the following criteria need to be met:

\section{Background and rationale}

- Do you consider how social norms, power relations and other structural factors underlying gender inequality affect your research topic, process and protagonists?

- Does your research analyse, recognize and seek to transform unequal power dynamics between men and women and/or other gender-diverse groups?

\section{Research design and methodology}

- Does the research strive for full and meaningful participation of different gender diverse and socially excluded groups as 'change agents' during different stages of the research cycle, including defining the research agenda, analysis, validation workshops, and use of the research results?

- Do the research questions explore the structural power relations that sustain gender inequalities in relation to the research topic? Do they address possible solutions and mechanisms for change with participants?

- Is there a research objective that identifies gendered barriers and seeks solutions?

- Will there be opportunities throughout the research cycle to be reflexive and aware of your own gender assumptions, biases and power as a researcher? 
- Do the Terms of Reference/Scope of Work recognize gender identity as a spectrum and consider the needs of gender-diverse communities?

- Do they consider the use of language, in particular the use of 'woman'/'man' when referring to social actors, and 'female'/ 'male', 'masculine'/ 'feminine' when referring to the construction of someone's social identity?

- Does the research methodology enable critical learning, reflection and questioning of gender inequality by all involved in the research process?

\section{Analysis}

- Does your power analysis consider gendered inequalities of power? What strategic approaches will be used for responding to them?

- Do the case studies highlight the initiative and agency of women, girls, and members of gender-diverse communities (rather than just portraying them as vulnerable and passive groups)?

\section{Dissemination and influencing}

- Are you explicitly challenging the harmful narratives around norms, power inequalities, patriarchy and other structural factors that promote gender inequalities in your messaging and communications?

- Do the solutions and recommendations you identify seek to lessen the impacts of gender inequality and also to fundamentally challenge and end it?

- Are there women's organizations that can be partnered with for the purposes of your research? If so, have you reached out to them?

\section{DOS AND DON'TS}

\begin{tabular}{|l|l|}
\hline Do & Don't \\
\hline $\begin{array}{l}\text { Recognize that not all research can be } \\
\text { gender-transformative - it depends on the } \\
\text { objectives, context and scope of the } \\
\text { research. Research that is embedded in } \\
\text { gender projects and programmes should } \\
\text { however aim to be gender-transformative. }\end{array}$ & $\begin{array}{l}\text { Use that as an excuse to limit what is } \\
\text { possible and not strengthen gender analysis } \\
\text { further. }\end{array}$ \\
\hline $\begin{array}{l}\text { Engage in a critical analysis and discussion } \\
\text { around how well gender can be integrated in } \\
\text { your research, and what are the challenges } \\
\begin{array}{l}\text { and opportunities. Treat this checklist as just } \\
\text { the start of your thinking about the gender } \\
\text { dynamics. }\end{array}\end{array}$ & $\begin{array}{l}\text { Limit yourself solely to the questions posed in } \\
\text { this guideline. }\end{array}$ \\
\hline $\begin{array}{l}\text { Consider men and other genders in your } \\
\text { analysis. Do include all relevant groups } \\
\text { (men, women, and others), as the position of } \\
\text { one cannot be understood in isolation from } \\
\text { the rest. }\end{array}$ & $\begin{array}{l}\text { Limit gender analysis to a focus only on } \\
\text { women and girls. }\end{array}$ \\
\hline
\end{tabular}


Incorporate a gender perspective throughout the research cycle (i.e. conceptualization of research topic, analysis, report writing and influencing). Adopt a reflective approach to questioning how well gender is being integrated at different stages of the research cycle.

Be reflexive and be aware of your own gender assumptions, biases, and power as a researcher.
Forget about the gender-integrated Terms of Reference or only consider gender towards the end of the research, once the report has been written and/or other outputs produced.

Assume that you as a researcher cannot bring your own gender biases and power to the research process.

\section{ADDITIONAL RESOURCES}

If you're looking to integrate gender in projects and programmes you might also find these resources useful:

\section{A Guide to Gender-Analysis Frameworks}

http://policy-practice.oxfam.org.uk/publications/aguide-to-gender-analysis-frameworks-115397

Quick Guide to Gender Analysis

https://policy-practice.oxfam.org.uk/publications/quick-quide-to-gender-analysis-312432

Gender Analysis and Integration Training Materials- Interagency Gender Working Group https://www.igwg.org/training/gender-analysis-and-integration/

Guidance on Mainstreaming Conflict Sensitivity, Gender and Social Inclusion in Research http://www.nsrp-nigeria.org/wp-content/uploads/2017/12/NSRP-How-to-Guide-MainstreamingConflict-Sensitivity-Gender-and-Social-Inclusion-in-Research.pdf

If you're looking for more information on research ethics from a gender perspective or in research on Gender-Based Violence, you might find these resources useful:

Sexual Violence Research Initiative - International Codes and Guidelines

http://www.svri.org/research-methods/ethics/international-codes-and-guidelines

Ethical and Safety Recommendations for VAWG Interventions

http://www.vawgresourceguide.org/ethics

\section{LINKS}

All links last accessed December 2018.

Writing Terms of Reference for Research: https://policypractice.oxfam.org.uk/publications/writing-terms-of-reference-for-research-253034

Terms of Reference for Research Template: https://policypractice.oxfam.org.uk/publications/terms-of-reference-for-research-template-253035

\section{Research for Influencing Diagram}


Interagency Gender Working Group 'Gender Integration Continuum Categories':

https://www.igwg.org/wp-content/uploads/2017/05/GendrContinuumCategories.pdf

(C) Oxfam International February 2019

This guideline has been prepared by the Oxfam Research Network (ORN) for use by development practitioners and researchers, including Oxfam staff and partners. It was written by Anam Parvez Butt (Oxfam GB), Namalie Jayasinghe (Oxfam America) and Mayssam Zaaroura (Oxfam Canada), and edited by Martin Walsh, with thanks to the ORN Gender Working Group, Irene Guijt, Fenella Porter and Patricia Espinoza for their inputs.

The text may be used free of charge for the purposes of education and research, provided that the source is acknowledged in full. The copyright holder requests that all such use be registered with them for impact assessment purposes. For copying in any other circumstances, or for re-use in other publications, or for translation or adaptation, permission must be secured and a fee may be charged. Email publish@oxfam.org.uk

Oxfam welcomes comments and feedback on its Research Guidelines. If you would like to discuss any aspect of this document, please contact research@oxfam.org.uk. For further information on Oxfam's research and publications, please visit www.oxfam.org.uk/policyandpractice

The information in this publication is correct at the time of going to press.

Published by Oxfam GB for Oxfam International under ISBN 978-1-78748-412-2 in February 2019.

Oxfam GB, Oxfam House, John Smith Drive, Cowley, Oxford, OX4 2JY, UK. Oxfam is a registered charity in England and Wales (no 202918) and Scotland (SC039042).

Oxfam is an international confederation of 20 organizations networked together in more than 90 countries, as part of a global movement for change, to build a future free from the injustice of poverty. 